\title{
The unseen face of humanitarian crisis in Eastern Democratic Republic of Congo: was nutritional relief properly targeted?
}

\begin{abstract}
Denis Porignon, Isu Katulanya, Lokombe Elongo, Nytha Ntalemwa, René Tonglet, Michèle Dramaix, Philippe Hennart
\end{abstract}

\begin{abstract}
Study objective-Comparison of children's nutritional status in refugee populations with that of local host populations, one year after outbreak refugee crisis in the North Kivu region of Democratic Republic of Congo.

Design-Cross sectional surveys.

Setting-Temporary and other settlements, in the town of Goma and surrounding rural areas.

Subjects-Anthropometric indicators of nutritional status and presence or absence of oedema were measured among 5121 children aged 6 to 59 months recruited by cluster sampling with probability proportional to size, between June and August 1995.

Results-Children in all locations demonstrated a typical pattern of growth deficit relative to international reference. Prevalence of acute malnutrition (wt/ht $<-2 \mathrm{Z}$ score) was higher among children in the rural non-refugee populations (3.8 and $5.8 \%$ ) than among those in the urban nonrefugee populations $(1.4 \%)$ or in the refugee population living in temporary settlements $(1.7 \%)$. Presence of oedema was scarcely noticed in camps $(0.4 \%)$ while it was a common observation at least in the most remote rural areas $(10.1 \%)$. As compared with baseline data collected in 1989 , there is evidence that nutritional status was worsening in rural non-refugee populations.
\end{abstract}

Scientific and Medical Centre of the Free University of Brussels (ULB) for its

Co-operation Actions CEMUBAC Team, Brussels (Belgium) and Goma (Democratic Republic of Congo)

D Porignon

I Katulanya

L Elongo

P Hennart

School of Public Health, Free University of Brussels (ULB), Brussels, Belgium D Porignon M Dramaix P Hennart

Oxford Famine Relief, Goma, Democratic Republic of Congo

$\mathrm{N}$ Ntalemwa

School of Public Health, Catholic University of Louvain (UCL), Brussels, Belgium

R Tonglet

Correspondence to: Dr P Hennart, CEMUBAC, School of Public Health, Free University of Brussels (ULB), Route de Lennik 808 (CP 595), B-1070 Brussels, Belgium.

Accepted for publication 25 April 1999
Conclusions-Children living in the main town or in the refugee camps benefited the most from nutritional relief while those in the rural non-refugee areas were ignored. This is a worrying case of inequity in nutritional relief.

(F Epidemiol Community Health 2000;54:6-9)

Deciding on how to distribute scarce nutritional resources in complex emergencies is a very difficult choice. ${ }^{1-3}$ The very need of targeting the most vulnerable does not preclude the possibility for the beneficiaries of being selected chiefly on the basis of easier access and narrow medical criteria. With this kind of selection, little consideration is given for the basic needs of all nutritionally vulnerable people, that is not only refugees and displaced persons but also the local host population.

Nutrition relief in the acute emergency phase limited to the management of therapeu- tic and supplementary feeding programmes almost exclusively targeted to accessible makeshift camps isolated from the local population is open to criticism. Focusing on selected beneficiaries is likely to contribute in the late emergency phase to marked differences in aggregate measures of nutritional status between or among population groups.

The uncertainty about the suitability of selection criteria and the possible consequences of unequal access to nutritional relief prompted us to study potential differences between children in refugee and national populations, one year after the outbreak of the Rwandan refugee crisis in the North Kivu region of Democratic Republic of Congo. ${ }^{4}$ The objective of this study is to compare the results of different nutritional surveys carried out during the same period among 6-59 month old children in refugee camps and in North Kivu urban and rural areas.

\section{Methods}

Between June and August 1995, cross sectional surveys were conducted on a sample of 5335 children aged 6-59 months. The study was based on children living in five refugee camps in the vicinity of the town of Goma, in two neighbouring rural health districts (Kirotshe and Masisi), and in the urban health district of Goma itself. All these settings were affected by the influx of Rwandan refugees.

Cluster sampling with probability proportional to size (PPS) was applied to select the samples. Sampling frame for cluster selection was the list of neighbourhoods in the urban area and in the camps and was the list of villages in rural areas. For each site, sample size was estimated before the survey. The sample size was obtained by first computing the number of subjects required to estimate the prevalence of malnutrition with sufficient precision under simple random sampling. In each surrounding, the anticipated prevalence introduced in these computations was chosen to be $50 \%$ (based on growth retardation prevalence observed in these regions). The absolute precision (width of $95 \% \mathrm{CI}$ ) was fixed at $5 \%$. The number of subjects obtained was then multiplied by 2 , the usual design effect considered in nutritional studies. As 30 clusters were planned in each site, the number of subjects in each cluster was simply the number of subjects estimated as described here above divided by 30. Theoretically, the subjects should have been selected by simple random sampling in 
Table 1 Characteristics of children according to surroundings

\begin{tabular}{llllll}
\hline & $\begin{array}{l}\text { Camps } \\
(n=2504) \\
\%\end{array}$ & $\begin{array}{l}\text { Goma } \\
(n=854) \\
\%\end{array}$ & $\begin{array}{l}\text { Masisi } \\
(n=929) \\
\%\end{array}$ & $\begin{array}{l}\text { Kirotshe } \\
(n=834)\end{array}$ & $p$ \\
\hline $\begin{array}{l}\text { Age } \\
6-11\end{array}$ & 8.3 & 11.4 & 10.3 & 13.2 & \\
$12-23$ & 19.6 & 25.5 & 21.3 & 21.1 & $<0.001$ \\
$24-35$ & 17.1 & 24.4 & 26.8 & 25.3 & \\
$36-47$ & 17.7 & 21.0 & 20.9 & 20.1 & \\
$48-59$ & 37.3 & 17.8 & 20.7 & 20.3 & \\
Sex & & & & & \\
Male & 50.4 & 48.2 & 49.1 & 49.5 & 0.714 \\
Female & 49.6 & 51.8 & 50.9 & 50.5 & \\
\hline
\end{tabular}

each cluster. However, a complete list of children was impossible to obtain. To constitute each cluster, a random direction was selected. The first house to be visited in that direction was chosen at random and the following houses chosen from one to the next till the sample was completed. All the children within the age range were weighted, measured and included in the sample.

All children were examined at home by trained auxiliary health workers closely supervised by nutrition technicians or qualified health professionals. Data were collected using standard methods for community nutritional assessment. ${ }^{5}$ Sex and age were collected. All the selected children were measured for weight and for height or length. Salter type scales were used to measure weight to the nearest 100 grams and locally constructed wooden boards were used to measure height or length to the nearest $\mathrm{mm}$. The presence of oedema, as indicator of protein deficiency, was also noted. Basic anthropometric indices (height for age (ht/a), weight for age (wt/a) and weight for height (wt/ht)) were computed in relation to the international reference and expressed in standard deviation units ( $Z$ scores). ${ }^{6}$

Some children with unknown age were included in the samples. The numbers (\%) of these children were $12(1.3 \%), 22(2.3 \%), 3$ $(0.3 \%)$ and $63(2.4 \%)$ for Kirotshe, Masisi, Goma and the camps respectively. In Kirotshe, 21 children were of an age outside the limits. These subjects as well as subjects with oedema or one with one of the anthropometric indices missing or markedly out of range $(-6<\mathrm{Z}$ score $<5)$ were excluded from all the analyses. The number of subjects with missing or out of range values were $156(2.9 \%), 118(2.2 \%), 53$ $(1.0 \%)$ and $37(0.7 \%)$ for ht/a, wt/a, wt/ht and oedema respectively.

As the camps present common characteristics (populations, standardised health and nutritional management), they were considered together in the analyses. Four groups of

Table 2 Proportions of malnutrition according to surroundings

\begin{tabular}{lllll}
\hline & Camps $(n=2504)$ & Goma $(n=854)$ & Masisi $(n=929)$ & Kirotshe $(n=834)$ \\
\hline \%<-2SD ht/a & 50.9 & 40.9 & 55.9 & 57.7 \\
(95\% CI) & $(48.1,53.7)$ & $(36.2,45.6)$ & $(51.4,60.4)$ & $(53.0,62.4)$ \\
\%<-2SD wt/a† & 27.5 & 19.3 & 38.2 & 35.9 \\
(95\% CI) & $(25.0,30.0)$ & $(15.6,23.0)$ & $(33.8,42.6)$ & $(31.3,40.5)$ \\
\%<-2SD wt/ht $\neq$ & 1.7 & 1.4 & 5.8 & 3.8 \\
(95\% CI) & $(1.0,2.05)$ & $(0.3,2.5)$ & $(3.7,7.9)$ & $(2.0,5.6)$ \\
\%Oedema & 0.4 & 1.8 & 10.1 & 1.0 \\
(95\% CI) & $(0.1,0.7)$ & $(0.5,3.1)$ & $(7.4,12.8)$ & $(0.0,2.0)$ \\
\hline
\end{tabular}

$\star_{\mathrm{ht}} / \mathrm{a}=$ height for age, $+\mathrm{wt} / \mathrm{a}=$ weight for age, $\neq w \mathrm{t} / \mathrm{ht}=$ weight for height.
KEY POINTS

- Distribution of scarce nutritional resources in complex emergencies is a very difficult decision to take.

- Remote rural areas that did not benefit by the humanitarian relief agencies appeared to be in a worse nutritional status than those areas that did benefit from them.

- Equitable distribution of nutritional relief has to take into account all the sectors of the population that become exposed to the aftermath of a disaster.

children were thus compared: those from refugee camps, those from Kirotshe, Masisi and Goma. For reasons explained above, 214 $(4.0 \%)$ subjects were excluded. The geographical distribution of these subjects was the following: $83(3.2 \%)$ in the camps, $32(3.6 \%)$ in Goma, $40(4.1 \%)$ in Masisi and $59(6.6 \%)$ in Kirotshe. The analyses were thus performed on data from 5121 subjects ( 2504 from the camps, 854 from Goma, 929 from Masisi and 834 from Kirotshe).

No significant difference was observed for sex, but age distribution differed significantly between the four sites (table 1). It was rather similar outside the camps whereas children from the camps seemed to be somewhat older. The percentages of $\mathrm{Z}$ scores $<-2$ were thus presented by age and location.

All data were analysed with EPI-Info 6.0 and the Statistical Package for Social Sciences. ${ }^{7}$ The $\chi^{2}$ test was used for comparisons of proportions. To take the design effect into account, the number of subjects was divided by 2 to compute standard errors. ${ }^{9}$

\section{Results}

Children in all locations showed a fairly typical pattern of growth retardation relative to the international reference (table 2). Globally, prevalence of height and weight growth retardation were both very high, but more children were short $(\mathrm{ht} / \mathrm{a}<-2 \mathrm{SD})$ than thin $(\mathrm{wt} / \mathrm{a}<-2$ $\mathrm{SD})$. Prevalence of acute malnutrition (wt/ht $<$ -2 SD or oedema) was much lower. There were significant differences between nutritional indices in the four settings. Non-refugee children living in the urban health district of Goma were the better off. Refugee children settled in the camps showed more severe growth deficits, but very few were observed with signs of acute malnutrition. Non-refugee children in the rural health districts of Kirotshe and Masisi had the worst nutritional indices, and a number of them suffered from acute malnutrition.

Prevalence of height for age and weight for age retardation increased with age and the differences between the four survey groups also varied according to age (table 3 ). In all age groups, prevalences of malnutrition in Goma were low. Prevalences of acute malnutrition were highest in Masisi and Kirotshe, except in the first age group where the prevalence in Kirotshe was lower than in the camps. For ht/a, differences between camps and the rural areas 
Table 3 Proportions of malnutrition according to age and surroundings

\begin{tabular}{|c|c|c|c|c|}
\hline & Camps & Goma & Masisi & Bulenga \\
\hline 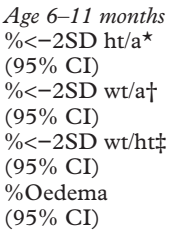 & $\begin{array}{l}n=208 \\
22.1 \\
(14.1,30.1) \\
19.2 \\
(11.6,26.8) \\
3.8 \\
(1.0,7.5) \\
0.5 \\
(0.0,1.9)\end{array}$ & $\begin{array}{l}n=97 \\
8.2 \\
(0.5,15.9) \\
6.2 \\
(0.0,13.0) \\
0.0 \\
\\
0.1 \\
(0.0,3.8)\end{array}$ & $\begin{array}{l}n=96 \\
32.3 \\
(19.1,45.5) \\
24.0 \\
(11.9,36.1) \\
7.3 \\
(0.0,14.7) \\
2.1 \\
(0.0,6.2)\end{array}$ & $\begin{array}{l}n=110 \\
23.6 \\
(12.4,34.8) \\
12.7 \\
(3.9,21.5) \\
2.7 \\
(0.0,7.0) \\
0.0\end{array}$ \\
\hline $\begin{array}{l}\text { Age } 12-23 \text { months } \\
\%<-2 \text { SD ht/a } \\
(95 \% \text { CI }) \\
\%<-2 \text { SD wt/a } \\
(95 \% \text { CI) } \\
\%<-2 \text { SD wt } / \mathrm{ht} \\
(95 \% \mathrm{CI}) \\
\% \text { Oedema } \\
(95 \% \mathrm{CI})\end{array}$ & $\begin{array}{l}n=490 \\
52.7 \\
(46.4,59.0) \\
28.6 \\
(22.9,34.3) \\
2.0 \\
(0.2,3.8) \\
0.6 \\
(0.0,1.6)\end{array}$ & $\begin{array}{l}n=218 \\
44.0 \\
(34.7,53.3) \\
20.2 \\
(12.7,27.7) \\
2.8 \\
(0.0,5.9) \\
1.8 \\
(0.0,4.3)\end{array}$ & $\begin{array}{l}n=198 \\
44.4 \\
(34.6,54.2) \\
37.9 \\
(28.3,47.5) \\
7.6 \\
(2.4,12.8) \\
5.6 \\
(1.1,10.1)\end{array}$ & $\begin{array}{l}n=176 \\
52.3 \\
(41.9,62.7) \\
30.7 \\
(21.1,40.3) \\
6.8 \\
(1.5,12.1) \\
1.1 \\
(0.0,3.3)\end{array}$ \\
\hline $\begin{array}{l}\text { Age } 24-35 \text { months } \\
\%<-2 \mathrm{SD} \mathrm{ht} / \mathrm{a} \\
(95 \% \mathrm{CI}) \\
\%<-2 \mathrm{SD} \mathrm{wt} / \mathrm{a} \\
(95 \% \mathrm{CI}) \\
\%<-2 \mathrm{SD} \mathrm{wt} / \mathrm{ht} \\
(95 \% \mathrm{CI}) \\
\% \text { Oedema } \\
(95 \% \mathrm{CI})\end{array}$ & $\begin{array}{l}n=429 \\
52.7 \\
(46.0,59.4) \\
27.0 \\
(21.1,32.9) \\
1.4 \\
(0.0,3.0) \\
0.2 \\
(0.0,0.8)\end{array}$ & $\begin{array}{l}n=208 \\
40.9 \\
(31.5,50.3) \\
19.7 \\
(12.1,27.3) \\
0.5 \\
(0.0,1.9) \\
0.5 \\
(0.0,1.9)\end{array}$ & $\begin{array}{l}n=249 \\
55.4 \\
(46.7,64.1) \\
36.9 \\
(28.4,45.4) \\
4.8 \\
(1.0,8.6) \\
11.6 \\
(6.0,17.2)\end{array}$ & $\begin{array}{l}n=211 \\
51.7 \\
(42.2,61.2) \\
40.8 \\
(31.4,50.2) \\
2.8 \\
(0.0,5.9) \\
2.4 \\
(0.0,5.3)\end{array}$ \\
\hline $\begin{array}{l}\text { Age } 36-47 \text { months } \\
\%<-2 \text { SD ht/a } \\
(95 \% \text { CI) } \\
\%<-2 \text { SD wt/a } \\
(95 \% \text { CI) } \\
\%<-2 \text { SD wt } / \mathrm{ht} \\
(95 \% \text { CI) } \\
\% \text { Oedema } \\
(95 \% \mathrm{CI})\end{array}$ & $\begin{array}{l}n=443 \\
65.9 \\
(59.7,72.1) \\
32.7 \\
(26.5,38.9) \\
1.1 \\
(0.0,2.5) \\
0.9 \\
(0.0,2.1)\end{array}$ & $\begin{array}{l}n=179 \\
44.1 \\
(33.8,54.4) \\
21.8 \\
(13.2,30.4) \\
1.7 \\
(0.0,4.4) \\
1.7 \\
(0.0,4.4)\end{array}$ & $\begin{array}{l}n=194 \\
63.9 \\
(54.3,73.5) \\
37.6 \\
(28.0,47.2) \\
5.2 \\
(0.8,9.6) \\
15.5 \\
(8.3,22.7)\end{array}$ & $\begin{array}{l}n=168 \\
70.8 \\
(61.1,80.5) \\
38.7 \\
(28.3,49.1) \\
2.4 \\
(0.0,5.7) \\
0.0\end{array}$ \\
\hline $\begin{array}{l}\text { Age } 48-59 \text { months } \\
\%<-2 \text { SD ht/a } \\
(95 \% \mathrm{CI}) \\
\%<-2 \mathrm{SD} \text { wt } / \mathrm{a} \\
(95 \% \mathrm{CI}) \\
\%<-2 \mathrm{SD} \mathrm{wt} / \mathrm{ht} \\
(95 \% \mathrm{CI}) \\
\% \text { Oedema } \\
(95 \% \mathrm{CI})\end{array}$ & $\begin{array}{l}n=934 \\
48.5 \\
(44.0,53.0) \\
26.4 \\
(22.4,30.4) \\
1.4 \\
(0.3,2.5) \\
0.2 \\
(0.0,0.6)\end{array}$ & $\begin{array}{l}n=152 \\
53.3 \\
(42.1,64.5) \\
23.0 \\
(13.5,32.5) \\
1.3 \\
(0.0,3.8) \\
3.9 \\
(0.5,8.3)\end{array}$ & $\begin{array}{l}n=192 \\
71.9 \\
(62.9,80.9) \\
47.9 \\
(37.9,57.9) \\
5.2 \\
(0.8,9.6) \\
11.5 \\
(5.1,17.9)\end{array}$ & $\begin{array}{l}n=169 \\
79.9 \\
(71.4,88.4) \\
47.3 \\
(36.7,57.9) \\
4.1 \\
(0.0,8.3) \\
0.6 \\
(0.0,2.2)\end{array}$ \\
\hline
\end{tabular}

$\star \mathrm{ht} / \mathrm{a}=$ height for age, $+w \mathrm{wt} / \mathrm{a}=$ weight for age, $\neq w \mathrm{wt} / \mathrm{ht}=$ weight for height.

were less pronounced between 12 and 47 months whereas within this age range, proportions of children with wt/a $<-2 \mathrm{SD}$ were always highest in the rural areas. Noteworthy, at 48-59 months, refugee and urban non-refugee children were almost similar with regard to weight or height and had much better nutritional indices than rural children.

\section{Discussion}

Our main finding is the demonstration of large differences between the nutritional status of population groups one year after exposure to a major public health emergency caused by population displacement in a region already confronted with long term severe nutritional problems. $^{10}$

With the sampling methodology followed in the surveys described here, possible bias may have influenced the results. As the households were not selected strictly at random, the sampling methodology diverged from standard PPS cluster sampling at the second stage of the sampling. The households were not selected independently of each other and households spatially related could have factors in common, such as access to food, standard of living or disease exposure. The resulting bias is difficult to quantify; the inclusion of adjacent households could result in over or under estimation of the population's true proportion of malnutrition. Other potential biases may occur if the interviewer has to decide which household is closest to the one just visited or if households found to be unoccupied at the time of the interviewer's visit are not revisited. Finally, a selection of the initial household not truly at random but rather based on grounds of convenience could also result in an important bias. In our surveys, the most important source of bias was certainly the first one. Unoccupied households were revisited and the initial household was chosen at random. The same methodology was applied to the different settings, the selection of the clusters was made at random, so it seems improbable that strictly random sampling should have led to no differences between the settings.

The urban host population in the town of Goma seems to be in a better nutritional status. In 1988, we observed in 2499 children aged 0-59 months that the prevalence of weight and height growth retardation was 32\% (95\% CI: $30 \%, 34 \%)$ and $67 \%$ (95\% CI: 65\%, 69\%) respectively, and that the prevalence of acute malnutrition was 5\% (95\% CI: 4\%, 6\%). ${ }^{10}$ In 1995 , there is evidence that children under 5 have a better nutritional status on average. Although nutritional indices are commonly considered to be better in urban settings than in rural ones, ${ }^{11}$ we assume from this observation that the population of Goma probably derived great advantage from the settlement in town of more than a hundred relief agencies boosting the local employment and money market. However, if this assumption may be relevant for weight growth retardation, it cannot entirely explain the improvement of the "height for age" anthropometric indicator. Nevertheless, despite this improvement, the observations made in 1988 and 1995 confirm the significant growth retardation in that part of Democratic Republic of Congo.

We know that in the camps, in July 1994, soon after the influx of Rwandan refugees into Democratic Republic of Congo, the prevalence of acute malnutrition among refugee children aged below 5 years ranged between 18 and $23 \%{ }^{4}$ A gradual decrease occurred in the camps during the next months. For example, in the Kibumba camp, the prevalence of acute malnutrition declined from 20.2\% (95\%CI: $16.1 \%, 25.0 \%$ ) in August 1994 to $6.3 \%$ (95\%CI: $4.0 \%, 9.5 \%)$ in October 1994 and 2.2\% (95\% CI: 0.8\%, 5.3\%) in December 1994 (UNCHR - Goma, unpublished nutritional report, 1995). At the time of this study, nutritional conditions among refugee children were stabilised with less than $2 \%$ of acute malnutrition. This is a good case for the efficiency of nutritional relief targeted to the camps, even when taking the survivor bias into consideration. ${ }^{12}$

In the rural health district of Kirotshe, nutritional indices in 1995 were slightly worse than those we collected in 1985 among 4459 children under $5 .{ }^{10}$ At the time, we had already observed large weight and height deficits, along with a roughly balanced weight for height. This suggested that the children from Kirotshe 
could more or less adapt to the typical ecosystem of the Kivu Highlands. ${ }^{13}$ However, nutritional adaptability in humans remains a controversial issue, ${ }^{14}$ and we argue that these children with "relative malnutrition" are certainly among the most nutritionally vulnerable and should deserve the same attention as those settled in camps.

In Masisi, which is a more remote rural area, nutritional problems that arose in 1995 were strikingly more severe than before the refugee crisis. In 1988, the prevalence of height for age, weight for age and weight for height deficits among 11253 children under 5 years old were $52 \%$ (95\% CI: $51 \%$, 53\%), 29\% (95\% CI: $28 \%$, $30 \%)$ and $2.6 \% \quad(95 \% \mathrm{CI}: 2.3 \%, 2.9 \%)$ respectively. ${ }^{10}$ At that time, less than $5 \%$ of the children between 12-59 months were with oedema. The worrying observations we made one year after the beginning of the refugee crisis, point to the many "indirect" victims of this crisis who also had acute needs and ought to have equally benefited from nutritional relief.

The lesson we draw from the observations made in this particular context is that focusing almost exclusively on the "direct" victims of a major public health emergency is questionable with regard to the issue of equity in health intervention. Although malnutrition usually decreases in the late emergency phase among refugee children settled in camps, it may obviously persist or worsen in other vulnerable groups of the local host population facing other unfavourable conditions (that is, socioeconomic breakdown, interethnic conflicts). Therefore it would be recommendable for equitable distribution of nutritional relief to take into account the whole population exposed to the aftermath of a complex disaster: refugees, displaced persons, not forgetting the local host population.
Data collected in the camps were kindly provided by the UNHCR team in Goma, Democratic Republic of Congo to which we would like to express our grateful thanks. The authors would like to thank the David and Alice Van Buuren Foundation in Brussels, Belgium. The authors would also like to thank Dr André Briend for comments on a former version of this manuscript.

Funding: the health activities of the CEMUBAC in Eastern Democratic Republic of Congo are funded by the Commission of the European Union (DG VIII) and by the Belgian governmental agency for co-operation in development governmental agency for co-operation in development the "Fonds de la Recherche Scientifique et Médicale (FRSM) (grant no: 3.4510.96).

Conflicts of interest: none.

1 Burkholder BT, Toole MJ. Evolution of complex disasters. Lancet 1995;346:1012-15.

2 Godfrey N. Supplementary feeding in refugee populations: comprehensive or selective feeding programmes? Health Policy and Planning 1986;1:283-98.

3 Seaman J. Management of nutrition relief for famine affected and displaced populations. Trop Doct 1991;21 (suppl 1):38-42.

4 Goma Epidemiology Group. Public health impact of Rwanan refugee crisis: what happened in Goma, Zaire, in July, 1994? Lancet 1995;345:339-44.

5 World Health Organisation. The use and utilisation of anthropometry. Geneva: WHO Tech Rep Ser 854, 1995.

6 National Center for Health Statistics (NCHS). NCHS growth curves for children birth-18 years, United States. Washington DC: US Department of Health Education and Welfor (DHEW publication no (PHS) 78-1650)

7 Dean AD, Dean JA, Coulombier D, et al. Epi Info version 6: a word processing, database, and statistics program for epidemiolword processing, database, and statistics program for epidemiolControl and Prevention, 1994.

8 Norusis MJ, ed. SPSS statistical data analysis for Windows, Release 6.1. Chicago: SPSS Inc, 1994.

9 Levy PS, Lemeshow S. Sampling of populations - methods and applications. NewYork: John Wiley, 1991

10 Tonglet R, Katulanya I, Chiabrera F, et al. Pattern of attained growth in 0 to 5 year-old children from Kivu (Zaire). Ecology of Food and Nutrition 1991;26:215-26.

11 Sommerfelt AE, Stewart MK. Children's nutritional status. DHS Comparative Studies no 12. Calverton, MD: Macro International Inc, 1994.

12 Boerma JT, Sommerfelt AE, Bicego GT. Child anthropomotry in cross-sectional surveys in developing countries: an assessment of the survivor bias. Am ₹ Epidemiol 1992;135: 438-49.

13 Wils W. Malnutrition in Central Africa. In: Mosley WH, ed. Nutrition and human reproduction. New York: Plenum Press, 1978:325-43.

14 Waterlow JC. Protein energy malnutrition. London: Edward Arnold, 1992:187-205. 